\title{
Discrete Wavelet Transform Based Fault Analysis and Identification in Flexible HVDC Transmission System
}

\author{
ZhiGuo Zhou ${ }^{1, a^{*}, \text { QiYing Jin }}{ }^{1, b}$ and Yi Zhang ${ }^{2, c}$ \\ ${ }^{1}$ School of Information and Electronics, Beijing Institute of Technology, Beijing 100081, China; \\ ${ }^{2}$ State Grid Fujian Electric Power Research Institute, Fuzhou 350007, Fujian Province, China \\ azhiguozhou@bit.edu.cn, binqiying1208@163.com, 'czhangyiscu@163.com \\ * the corresponding author
}

Keywords: HVDC flexible; Mallat algorithm; three-phase ground fault; DC line fault.

Abstract. The accuracy of fault detection is helpful to improve the stability of power quality. With the development of new energy, the technology of flexible HVDC transmission has been gradually mature, but there are still some problems. In this paper, the Mallat algorithm is used to detect the DC line fault and three-phase grounding fault in the flexible HVDC system. The high frequency wavelet coefficient amplitude obtained by Mallat decomposition is used to distinguish the fault type. The simulation results show that after wavelet decomposition of fault voltage has the modulus maxima. We can judge the fault type by the value of the modulus maximum, its maximum value is the starting and ending time of the fault, and the fault detection accuracy error is within $1 \%$.

\section{Introduction}

The flexible HVDC transmission system, which is composed of a power off device, a pulse width modulation (PWM) technology, and a voltage source converter, is becoming more and more popular. Compared with the traditional direct current transmission system, the characteristics of active and reactive power, fast running mode, flexible operation mode and so on ${ }^{[1]}$. The above advantages make the flexible HVDC system in the new energy transmission areas (such as renewable energy generation, wind power grid, weak electricity network, etc.) has a wide range of development prospects ${ }^{[2]}$. But there are some limitations in the flexible HVDC transmission system : By mechanical stress factors produced DC fault ${ }^{[3]}$, three-phase grounding fault ${ }^{[4]}$ introduced will cause the fault current of VSC overload and feed circuit will lead to IGBT with diode is connected in parallel with the out of control, so that the devices appear as voltage interruption, surge et al. The switch loss is easy to generate DC side fault voltage and AC side grounding fault. But the traditional measurement can not meet the measurement and analysis of the above problems, and therefore need to be more precise, flexible and efficient method for power quality detection. It requires the ability to capture the instantaneous interference waveform for flexible HVDC transmission systems, including fault caused by voltage interruptions and disturbances.

Due to the application of new power electronic devices, the transmission system has become more and more complex, which will make the power quality problems become more prominent, it is difficult to analyze the fault and protect power grid operation. However, the lack of effective detection means and the ability to judge the fault.We can not grasp the situation of power grid stability is an important factor lead to the power failure accident. Based on this, a new wavelet decomposition process is proposed by [5], decomposition wavelet coefficients real-time analysis and detection of power system transient power signal disturbance problems. Ref. [6] studied under transient conditions, various types of fault problems HVDC system using wavelet transform to determine fault current rise time and oscillation mode, based on the detected results to determine whether to execute trip protection circuit. In this paper, a fault monitoring and recognition system for flexible HVDC transmission system is constructed. Monitoring and identification of DC fault, three-phase grounding fault through the Mallat algorithm. Using MATLAB/Simulink as the development environment, the VSC-HVDC system model is built and analyzed, and the simulation 
results are carried out in the circuit. Mallat algorithm based on discrete wavelet transform to distinguish the fault voltage. To extract the Modulus maximum of the disturbance point, and analyze the causes of the fault.

\section{Fault Detection point for Flexible HVDC Transmission System}

The flexible HVDC system is composed of three parts, such as the rectifier station, the DC circuit and the inverter station, as is shown in Fig. 1. The main equipment of the station named converter, its purpose is to achieve the conversion of AC and DC.Voltage source converter (VSC) is the core of the Flexible HVDC transmission system, which is used to complete the power transformation and generate the sine wave. The main device IGBT can be switched off in high speed, the PWM technology is introduced into the basic model of VSC.Compared by the modulation wave and triangular carrier, generating corresponding trigger pulse control IGBT turn-on and turn-off.

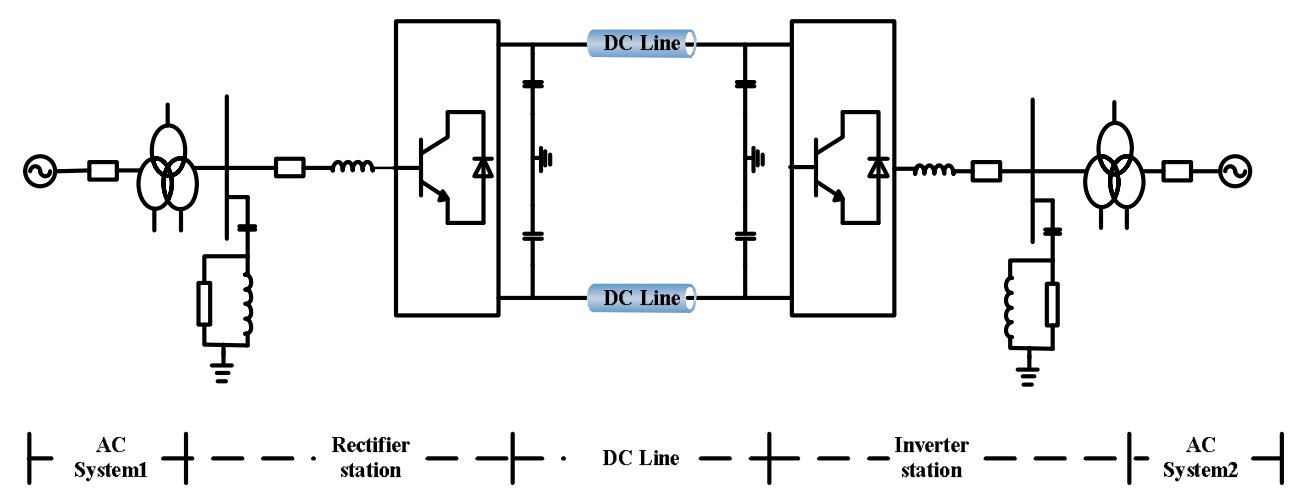

Fig.1. HVDC flexible system schematic

DC fault detection point. AC and DC port of flexible HVDC transmission system is easy to be influenced by external mechanical stress. Suitable fault identification is an important factor to protect the normal operation of the flexible HVDC system. The feasibility of using Mallat algorithm to detect the DC fault is analyzed in this paper. Common faults in DC transmission line - line fault and line to ground fault. In this paper, we mainly study the grounding fault of the DC line. The simulation analysis is carried out, and the $75 \mathrm{~km}$ cable is modeled as a ground fault, as is shown in Fig. 2.

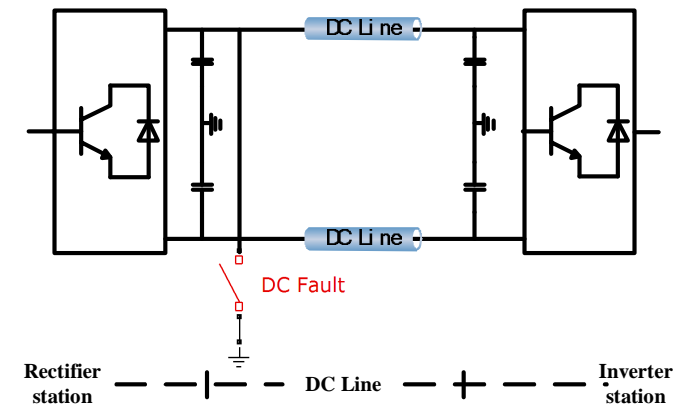

Fig.2. DC-side fault

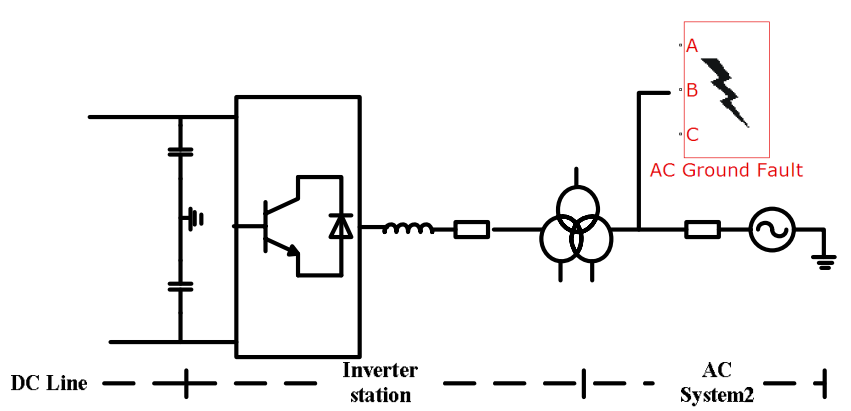

Fig.3. Three phase grounding fault

Three-phase ground fault detection point.Under various operating conditions, the dynamic characteristics of the flexible HVDC transmission system (e.g., AC system fault and transient state, $\mathrm{AC}$ voltage disturbance, etc.) are evaluated. The sending end and the receiving end are respectively injected into three phase grounding fault, MATLAB/Simulink simulation is performed to distinguish the different kinds of fault characteristics. The fault source is the VSC output of the inverter station with a short circuit, as is shown in Fig. 3. 


\section{Implementation of Mallat algorithm and filter bank.}

Discrete wavelet transform is used in the field of signal de-noising and processing, image, voice and so on. The Mallat algorithm which is based on resolution analysis multi (MRA) is proposed by French scientist S.Mallat in 1988. According to the theory of multi - resolution analysis, the two scale equation of the scale function $\phi(t)$ and the two - scale equation of wavelet function $\psi(t)$ satisfy the following Eq. (1) and Eq. (2):

$$
\begin{gathered}
\phi(t)=\sqrt{2} \sum_{-\infty}^{+\infty} h(k) \varphi(2 t-k) \\
\psi(t)=\sqrt{2} \sum_{-\infty}^{+\infty} g(k) \varphi(2 t-k)
\end{gathered}
$$

We do not need to know the details of the scale function and the wavelet function, only need to know the filter coefficient. Then we can realize the decomposition and reconstruction of the signal.

The basic idea of the realization of the filter bank is to obtain the original signal through a high pass filter (HP) and a low pass filter (LP). Solving the first level wavelet transform, then the low frequency part of the first level transformation is decomposed by high and low filter. In general, the base frequency of the signal is located at the center of the lowest frequency band, and select the appropriate decomposition level. According to the first level and the second level high frequency coefficient to determine the location of the mutation, so as to determine the type of fault and the cause of failure in VSC-HVDC system. Fig. 4 is a Mallat algorithm discrete signal decomposition and signal spectrum.

In this paper, the DB5 wavelet in Daubechies filter is used to analyze the mutation signal. DB5 wavelet is suitable for the detection of transient power quality. The experimental results show that the high frequency coefficients of the first layer and the second layer have a modulus maximum, which can determine the starting and ending time of the fault.

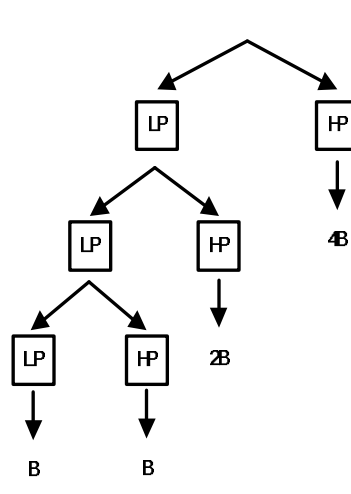

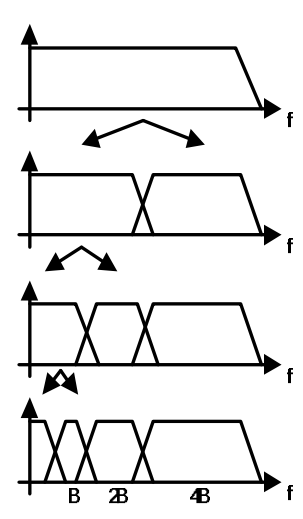

Fig.4. Mallat decomposition algorithm and signal spectrum
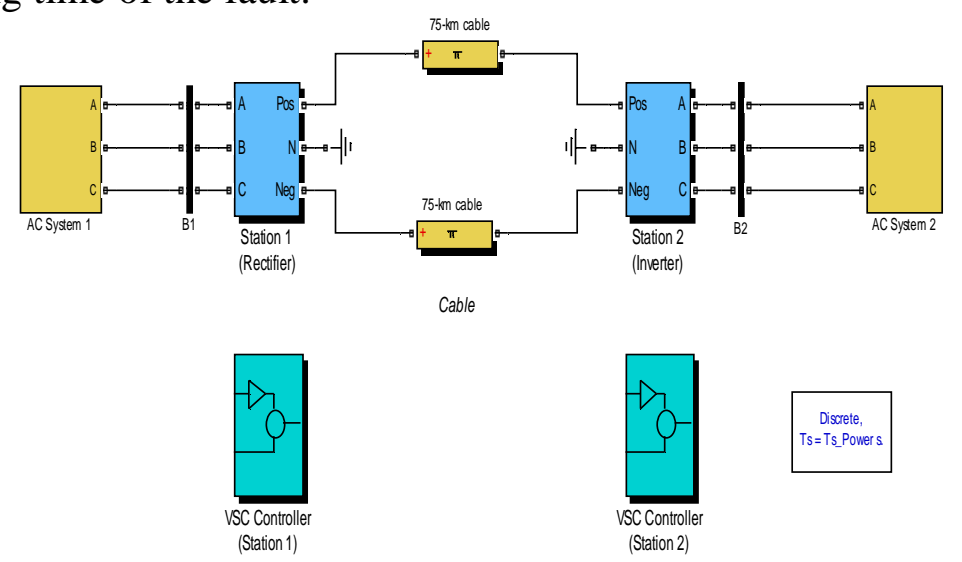

Fig.5. VSC-HVDC system model

\section{MATLAB simulation}

VSC HVDC system simulation model.In this paper, the power system module (SimPowerSystems) is applied to the MATLAB/Simulink system, and the simulation module is used to build the simulation model of VSC-HVDC system, as shown in Fig.5. In this model, a 2000MW, 230kV, $50 \mathrm{~Hz}$ AC system (transmission side) through the voltage source converter force a complementary 200MW, 100KV DC system, after the HVDC transmission line is converted into another AC system (receiving side). Along with the converters, the station includes on the AC side: the step down Yg-D transformer, the AC filters, the converter reactor; and on the DC side: the capacitors, the DC filters. The Sinusoidal Pulse Width Modulation (SPWM) switching uses a single-phase 
triangular carrier wave with a frequency of 27 times fundamental frequency $(1350 \mathrm{~Hz})$. The sampling time of the whole power system is Ts_Power=7.407e-6s, the sampling time of the control system is Ts_Control=74.07e-6s, which is a multiple of the carrier period. Using variable step mode single-step solver ode45 (four / five Runge - Kutta method), which is characterized by continuous or discrete for most systems, but not for a rigid system, the system calculated values are accurate to $0.1 \%$.

Three phase grounding fault. Three phase grounding fault is considered as one of the major fault of the flexible HVDC transmission system. Fault grounding lead to voltage sag and interruption. And caused the grounding current rise due to short circuit, become the preferred target of power quality detection. Simulation analysis of the three phase grounding fault using MATLAB/Simulink. From the above, the A phase in the system is running to the $0.101 \mathrm{~s} \sim 0.102 \mathrm{~s}$ to set the ground fault, as shown in Fig. 6 is a simulation of receiving side a three-phase ground fault wave detection. From the graph, we can see that the phase voltage sag caused by A is interrupted and the voltage stability of B and C phase is affected. Inverter station and receiving side system's high potential difference that causes the A-phase current swells about to $16 \mathrm{kA}$. Because the fault point is close to the inverter, the DC circuit is relatively stable, but the inverter side is obvious.

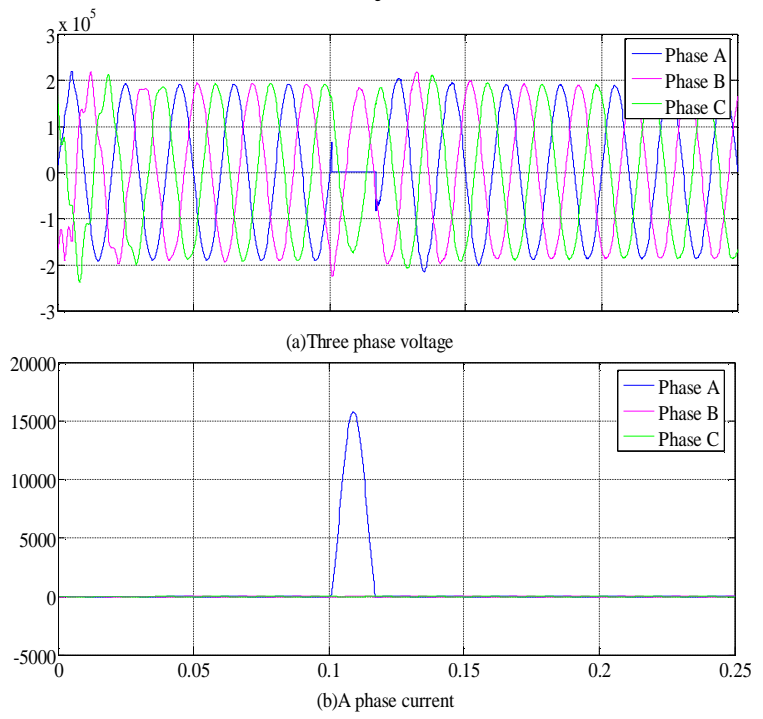

Fig.6. A phase fault voltage and fault current
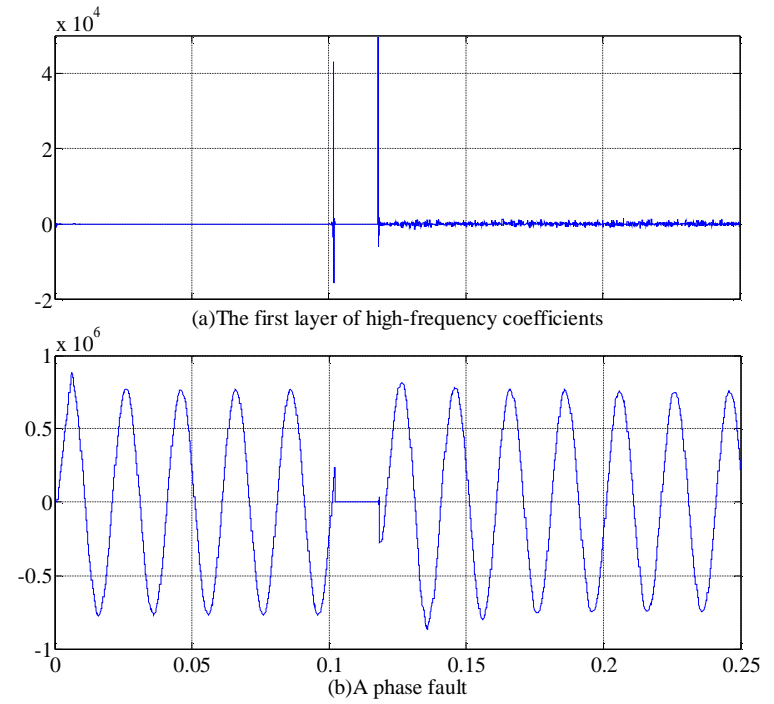

Fig.7. A phase ground fault detection

Mallat algorithm based on discrete wavelet transform for fault detection. Constructed linear filter bank, high pass filter and low pass filter coefficients of DB5 wavelet are acquired by wfilters ('wavename'). The following Eq.(3) and Eq.(4) are respectively.

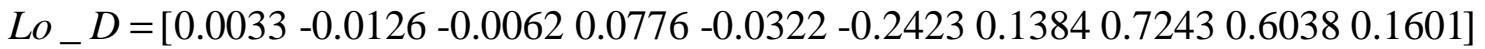

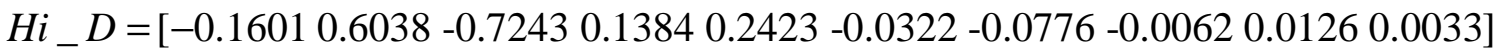

Simulation results show that the coefficients of the $0.101 \mathrm{~s}$ and $0.102 \mathrm{~s}$ in Fig.7 have obvious modulus maxima, and the location of the maximum value point can be determined by the position of the detected value point.

DC line fault. When the VSC-HVDC system has a direct current side fault (DC Fault), the fault time is $1.301 \mathrm{~s}$. DC line fault and fault-free access comparison shown in Fig. 8. From Fig. 8 it can be seen that there is a fluctuation in the positive voltage of 1.301s. Fig.9 is a first layer of high-frequency decomposition coefficients fault waveforms can be seen from the figure modulus maxima exist at $1.301 \mathrm{~s}$ place.

Table.1 Wavelet coefficients and catastrophe voltage relationship

\begin{tabular}{lc}
\hline Type & First wavelet coefficient peak \\
\hline DC side fault & 49 \\
Three phase grounding fault & $4.4 \times 10^{4}$ \\
\hline
\end{tabular}

The following table 1 is summarized in Fig. 7 and Fig.8. In the premise of the detection of fault time, the increase of wavelet coefficients can be used as an important method to distinguish the type 
of fault. From table 1 it can be seen that when the wavelet coefficient is high, it can be considered as the power quality problem caused by three phase grounding. Thus, the rapid rise of the fault current implies high wavelet coefficients.

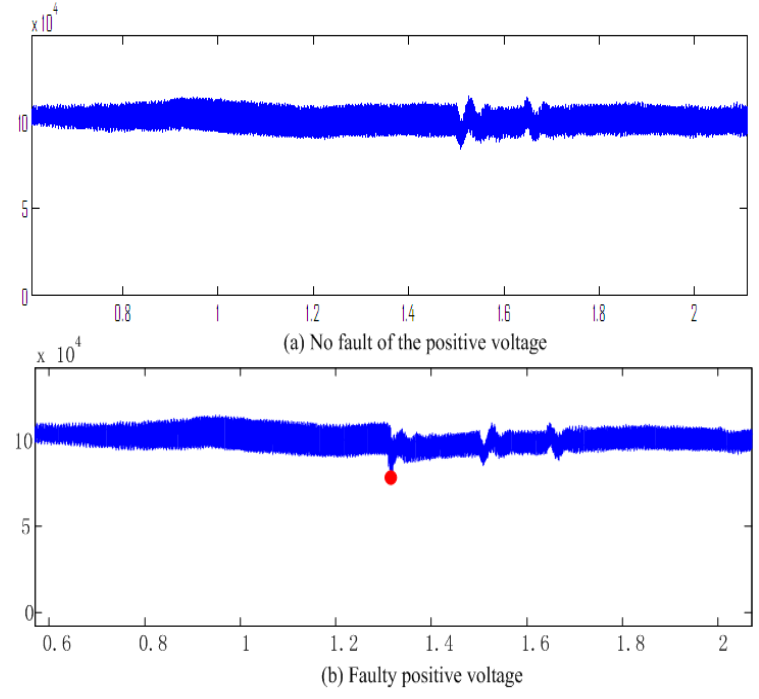

Fig.8. DC-side fault voltage fluctuation

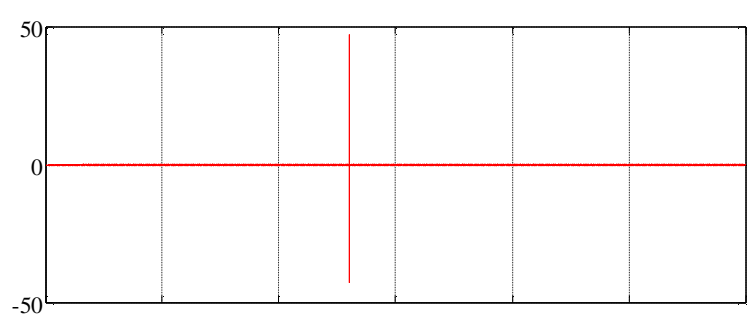

(a) First layer high frequency coefficient

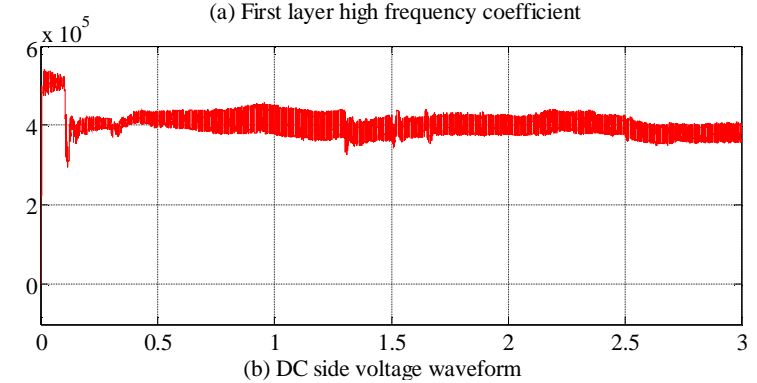

Fig.9. DC-side fault detection

\section{Conclusions}

Trouble problem is the problem of the power sector and users are very concerned. As a new type of transmission system, the fault problem of the flexible HVDC system is not to be underestimated, for the correct analysis is placed in front of the electrical engineer major problem. In this paper, we propose a set of AC inverter and DC line ports for the fault detection. Mallat discrete wavelet algorithm for three phase grounding fault, DC fault detection. Simulation results show that the Mallat wavelet analysis is used as a feasible tool to determine the time and the time of the failure, and to identify the DC fault and the three-phase grounding fault. Through the wavelet coefficients of the two kinds of fault to determine the size of the three-phase ground fault and DC side fault.

\section{Acknowledgements}

This work was supported in part by Research on the Influence of Power Quality of the Power Network in the Flexible HVDC Project.We would like to thanks the State Grid Fujian Electric Power Research Institute of China.

\section{References}

[1] J. Dorn, H. Huang, D. Retzmann: Proceedings of Cigre Conference, 2008.

[2] G. F. Tang: Power System Technology, Vol. 36(2012), pp. 1-6(in Chinese).

[3] D. J. Xing, J. L. Wu, X. W. Wang, W. Z. Yao: Power System Technology, Vol. 39(2015), pp. 1825-1832(in Chinese).

[4] M. Karthikeyan, Yew Ming Yeap, A. Ukil: In Industrial Electronics Society, IECON 2014 40th Annual Conference of the IEEE, (2014), pp. 1786-1791.

[5] F. B. Costa: Power Delivery, IEEE Transactions on, vol. 29(2014), pp. 2674-2687.

[6] Yew Ming Yeap, A. Ukil: Industrial Electronics Society, IECON 2014 - 40th Annual Conference of the IEEE, (2014), pp. 2472-2478. 